\title{
The effect of probiotic ice cream consumption on salivary cariogenic bacteria in healthy adults
}

\author{
Dominika Češek, Katja Bezek, Boris Kovač \\ University of Primorska, Faculty of Health Sciences, Polje 42, 6310 Izola, Slovenia \\ cesek.dominika@gmail.com; katja.bezek@fvz.upr.si; boris.kovac@fvz.upr.si
}

\begin{abstract}
Introduction: Oral microbiota is one of the most important and complex microbial communities in the human body. Microbiota dysbiosis can however lead to common diseases, including dental caries and periodontitis, and also systemic diseases. Dental caries represents one of the most common chronic diseases worldwide and is characterized by the localized destruction of the mineralized tooth tissues caused by bacterial action. There is a positive correlation between dental caries, frequency and amount of consumed dietary sugars, together with other factors influencing its development, including oral hygiene, salivary flow and composition and also enamel defects. Additionally, Streptococcus mutans was shown as one of the most dental-caries related bacteria species. Since the traditional approaches are often insufficient in reducing the numbers of caries causing organisms, alternative approach such as probiotics consumption were proposed. Thus, the aim of the present study was to test the effect of probiotic ice cream on salivary cariogenic bacteria counts in healthy adults. Methods: In the double-blind, placebo-controlled study 11 healthy participants (10 females, 1 male), aged 20-50 years, were included. Saliva samples were collected using CRT ${ }^{\oplus}$ bacteria test at day o and after 2 weeks of ice cream consumption. Probiotic ice cream contained two probiotic strains Bifidobacterium animalis subsp. lactis $\mathrm{BB}-12^{\oplus}$ (nu-trish ${ }^{\circledR} \mathrm{BB}-12^{\circledR}$ ) in concentration of $2,8 \times 10^{8} \mathrm{CFU} / \mathrm{g}$ and Lactobacillus acidophilus (nu-trish ${ }^{\odot}$ LA- $5^{\oplus}$ ) in concentration of $1,1 \times 10^{8} \mathrm{CFU} / \mathrm{g}$. Participants also completed questionnaires about knowledge and frequency of probiotics and cariogenic food consumption and a questionnaire on ice cream opinion. Results: After 2 weeks of consumption, the salivary cariogenic bacteria count in the control group of participants were the same or even higher, when compared to day o. On the other hand, for participants consuming probiotic ice cream, $S$. mutans counts were lower with corresponding
\end{abstract}


higher Lactobacillus counts. The total viability counts of probiotic bacteria did not change with time during 120-day storage. Although the participant's knowledge about probiotics was adequate, there was a lack of knowledge observed regarding the term "cariogenic food". Discussion and conclusion: Despite the small sample of participants, a trend of lower salivary cariogenic S. mutans and corresponding higher Lactobacillus counts were observed in participants consuming probiotic ice cream. Based on the results, probiotics consumption could be included in the prevention of dental caries, however larger-scale study should be conducted to confirm the significance of our results. Nevertheless, due to the observed lack of knowledge about probiotics and cariogenic foods the theoretical and practical approaches should be suggested for healthier eating habits of working-age population.

Keywords: oral microbiota, dental caries, Streptococcus mutans, probiotics

\section{Introduction}

Oral microbiota is one of the most important and complex microbial communities in the human body (Lamont et al., 2018). Moreover, there is an increasing number of evidences demonstrating that oral microbiota dysbiosis is associated not only with oral diseases (Li et al., 2019), including dental caries and periodontal disease (Costalonga and Herzberg, 2014), but also systemic diseases (Graves et al., 2018). Dental caries, one of the most common chronic diseases worldwide, is characterized by the localized destruction of the mineralized tooth tissues caused by bacterial action (Jin et al., 2015; Marsh and Zaura, 2017). The onset of dental caries is positively correlated to the amount and frequency of consumed dietary sugars (van Loveren, 2019), which can be mostly found in cariogenic foods. Additional host factors influencing dental caries development, such as oral hygiene, salivary flow and composition, and enamel defects, are also important (Lamont et al., 2018). Since S. mutans was characterised as one of the most common causes for dental caries development (Loesche, 1986) against which traditional approaches were not successful (Mahantesha et al., 2015), newer approaches such as probiotics have been tested (Anderson and Shi, 2006). Probiotics are live microorganisms which when administered in an adequate amount confer health benefits on the host (FAO and WHO, 2002). Regarding dental caries, the main goal of probiotic application is to replace cariogenic with noncariogenic bacteria (Twetman and Keller, 2012). As shown before, probiotics were shown to have a beneficial effect on oral health (Bonifait et al., 2009; Devine and Marsh, 2009). The aim of the present study was to investigate the effect of daily ice cream consumption containing probiotic strains B. animalis subsp. lactis BB-12 and L. acidophilus LA-5 on salivary S. mutans counts in healthy individuals. 


\section{Methods}

In the present double blind, placebo-controlled study 11 healthy participants, ten females, and one male, aged 20-50 years, who met the inclusion criteria were included. Inclusion criteria involved restrictions of antibiotics and probiotic dietary supplements consumption, orthodontic apparatus, and cavity injuries. Participants were scheduled for 2 visits. In the first visit, they completed two questionnaires about the knowledge and frequency of probiotic and cariogenic foods consumption and gave saliva sample, followed by a 14-day period of $60 \mathrm{~g}$ ice cream consumptions. In the second visit, they completed the questionnaire regarding product feedback, followed by saliva sampling using CRT ${ }^{\circ}$ bacteria test (Ivoclar Vivadent, Liechtenstein). The ice cream base is a trade secrete (Incom d.o.o., Ajdovščina, Slovenia), while probiotic ice cream contained two probiotic strains B. animalis subsp. lactis BB-12 (nu-trish ${ }^{\circ} \mathrm{BB}-12^{\circ}$ ) and L. acidophilus (nu-trish ${ }^{\circ}$ LA- $5^{\circ}$ ) (Chr. Hansen, Denmark) in final concentration of $2,8 \mathrm{x}$ $10^{8} \mathrm{CFU} / g$ and $1,1 \times 10^{8} \mathrm{CFU} / g$, respectively. As negative control ice cream without probiotics supplementation was used. For the statistical analysis, Microsoft Excel 2016 and IBM SPSS version 26 were used.

\section{Results}

To begin with, most of the participants brush their teeth 1-2 times daily without the use of dental floss. The majority of participants $(66,4 \%)$ were familiar with the term "probiotics" and their use. However, 55,4\% of participants neither agreed, nor disagreed with the statement that probiotic consumption slows down the growth of microorganisms that cause caries in the oral cavity. Regarding the consumption of foods containing live microorganisms possessing probiotic properties, the most commonly reported were yoghurt and cheese, with minimal consumption amounts of $150 \mathrm{ml} /$ week and 22,5 g/week. Lack of knowledge was observed in the category of "cariogenic foods", while the most frequently consumed cariogenic foods were fruit juice and ice cream, followed by jam and biscuits. Regarding cariogenic bacteria counts in saliva samples, the salivary $S$. mutans counts in the control group after 14-day ice cream consumption were the same or even higher compared to day o and for most cases there was no change in Lactobacillus counts. In the experimental group with 14-day probiotic ice cream consumption, salivary S. mutans counts were lower with corresponding higher Lactobacillus counts. Nevertheless, according to data of appearance, taste, scent and texture of the ice cream, participants liked the product.

\section{Discussion}

Obesity and dental caries are widespread pathologies, triggered by common etiologic factors, such as high added sugar consumption already in childhood (Delli Bovi et al., 2017). Furthermore, fermentable dietary carbohydrates, among which sucrose is considered the most cariogenic, are the key factors 
involved in the initiation and development of dental caries (Paes Leme et al., 2006). Thus, low $\mathrm{pH}$ level as a result of carbohydrate fermentation, triggers a shift of cariogenic oral microbiota, resulting in enamel demineralization (Delli Bovi et al., 2017). Despite the low number of participants of the present study, their lack of knowledge about cariogenic foods is of big concern. Moreover, the cariogenic foods, defined with the presence of fermentable carbohydrates does not affect their shopping habits. In contrast to cariogenic foods, the knowledge about probiotics was better, since the majority of participants was familiar with the term and use. According to the consumption of listed foods, only 2 out of the 11 participants met the recommended daily intake of probiotic microorganisms. That should be a minimum of $10^{6} \mathrm{CFU} / \mathrm{ml}$ of product (Boylston et al., 2004). Since the probiotics had been proven as successful in dental caries prevention, the aim of this study was to test the effect of probiotic ice cream on salivary cariogenic bacteria in healthy adults. Based on CRT values after participant's saliva sampling, it was shown that the used probiotic strains influenced salivary S. mutans counts which were lower compared to day o. Probiotic icecream affected also Lactobacillus counts which is important for maintaining healthy oral microbiota.

\section{Conclusion}

Among participants a lack of knowledge about probiotics and cariogenic food was observed, therefore the theoretical and practical approaches should be suggested for healthier eating habits. Participants who consumed probiotic ice cream with 2 different probiotic strains had lower salivary cariogenic S. mutans counts and corresponding higher probiotic Lactobacillus concentration after 14-day ingestion period in comparison with participants in the control group. However, the main limitation of the study was low number of participants, thus a larger scale study should be conducted to confirm the significance of our results.

\section{References}

ANDERSON, M.H. and SHI, W., 2006. A probiotic approach to caries management [online]. Journal of Pediatric Dentistry, vol. 28, no. 2., pp. 151153. [viewed 15 May 2020]. Available from: http://www.ncbi.nlm.nih.gov/ pubmed/16708790

BONIFAIT, L., CHANDAD, F. and GREINER, D., 2009. Probiotics for oral health: myth or reality? [online]. Journal of the Canadian Dental Association, vol. 75, no. 8, pp. 585-590. [viewed 22 June 2020]. Available from: http://www.ncbi.nlm.nih.gov/pubmed/19840501

BOYLSTON, T.D., VINDEROLA, C.G., GHODDUSI, H.B. and REINHEIMER, J.A., 2004. Incorporation of bifidobacteria into cheeses: challenges and rewards [online]. International Dairy Journal, vol. 14, no. 5, pp. 375- 
387. [viewed 29 June 2020]. Available from: http://dx.doi.org/10.1016/j.idairyj.2003.08.008

COSTALONGA, M. and HERZBERG, M.C., 2014. The oral microbiome and the immunobiology of periodontal disease and caries [online]. Immunology Letters, vol. 162, no. 2, pp. 22-38. [viewed 14 May 2020]. Available from: http://dx.doi.org/10.1016/j.imlet.2014.08.017

DELLI BOVI, A.P., DI MICHELE, L., LAINO, G. and VAJRO, P., 2017. Obesity and obesity related diseases, sugar consumption and bad oral health: a fatal epidemic mixture. The pediatric and odontologist point of view. [online]. Translational Medicine Unisa, vol. 16, pp. 11-16. [viewed 26 June 2020]. Available from: http://www.ncbi.nlm.nih.gov/pmc/articles/ PMC5536157/

DEVINE, D.A. and MARSH, P.D., 2009. Prospects for the development of probiotics and prebiotics for oral applications [online]. Journal of Oral Microbiology, vol. 1 (Suppl.). [viewed 21 June 2020]. Available from: http://dx.doi. org/10.3402/jom.v1io.1949

FOOD AND AGRICULTURE ORGANIZATION (FAO) and WORLD HEALTH ORGANIZATION (WHO), 2002. Report of a joint FAO/WHO working group report on drafting guidelines for the evaluation of probiotics in food [online]. [viewed 15 May 2020]. Available from: http://www.who. int/foodsafety/fs_management/en/probiotic_guidelines.pdf

GRAVES, D.T., CORRÊEA, J.D. and SILVA, T.A., 2018. The oral microbiota is modified by systemic diseases [online]. Journal of Dental Research, vol. 98, no. 2, pp. 148-156. [viewed 20 June 2020]. Available from: http://dx.doi. org/10.1177/0022034518805739

JIN, L.J., LAMSTER, I.B., GREENSPAN, J.S., PITTS, N.B., SCULLY, C. and WARNAKULASURIYA, S., 2015. Global burden of oral diseases: emerging concepts, management and interplay with systemic health [online]. Oral Diseases, vol. 22, no. 7. [viewed 21 June 2020]. Available from: http:// dx.doi.org/10.1111/odi.12428

LAMONT, R.J., KOO, H. and HAJISHENGALLIS, G., 2018. The oral microbiota: dynamic communities and host interactions [online]. Nature Reviews Microbiology, vol. 16, no. 12, pp. 745-759. [viewed 22 June 2020]. Available from: http://dx.doi.org/10.1038/s41579-018-0089-x

LI, B., GE, Y., CHENG, L., ZENG, B., YU, J., PENG, X., ZHAO, J., LI, W., REN, B., LI, M., et. al., 2019. Oral bacteria colonize and compete with gut microbiota in gnotobiotic mice [online]. International Journal of Oral Science, vol. 11, no. 1, pp. 10. [viewed 15 May 2020]. Available from: http://dx. doi.org/10.1038/s41368-018-0043-9

LOESCHE, W.J., 1986. Role of Streptococcus mutans in human dental decay [online]. Microbiology Reviews, vol. 50, no. 4, pp. 353-38o. [viewed 15 May 2020]. Available from: http://www.ncbi.nlm.nih.gov/pmc/articles/ $\mathrm{PMC}_{373078 /}$ 
MAHANTESHA T., PARVEEN REDDY, K.M., PARVEEN KUMAR, N.H., NARA, A., ASHWIN, D. and BUDIGGA, V., 2015. Comparative study of probiotic ice cream and probiotic drink on salivary streptococcus mutans levels in 6-12 years age group children [online]. Journal of International Oral Health, vol. 7, no. 9, pp. 47-50. [viewed 16 May 2020]. Available from: http://www.ncbi.nlm.nih.gov/pmc/articles/PMC4589718/

MARSH, P.D. and ZAURA, E., 2017. Dental biofilm: ecological interactions in health and disease [online]. Journal of Clinical Periodontology, vol. 44, no. 18. [viewed 22 June 2020]. Available from: http://dx.doi.org/10.1111/ jcpe.12679

PAES LEME, A.F., KOO, H., BELLATO, C.M., BEDI, G. and CURY, J.A., 2006. The role of sucrose in cariogenic dental biofilm formation-new insight [online]. Journal of Dental Research, vol. 85, no. 10, pp. 878-887. [viewed 29 June 2020]. Available from: http://dx.doi.org/10.1177/154405910608501002

+ TWETMAN, S. and KELLER, M.K., 2012. Probiotics for caries prevention and control [online]. Advances in Dental Research, vol. 24, no. 2, pp. 98-102. [viewed 23 June 2020]. Available from: http://dx.doi. org/10.1177/0022034512449465

VAN LOVEREN, C., 2019. Sugar restriction for caries prevention: amount and frequency. Which is more important? [online]. Caries Research, vol. 53, no. 2, pp. 168-175. [viewed 22 June 2020]. Available from: http://dx.doi. org/10.1159/000489571 